\title{
PEMANFAATAN LIMBAH PLASTIK MENJADI KEMASAN RAMAH LINGKUNGAN SERTA UJI BIODEGRADASINYA
}

\author{
Asiska Permata Dewi ${ }^{1)}$, Yulia Yesti ${ }^{2)}$ \\ 1) Analis Farmasi dan Makanan Universitas Abdurrab \\ Jl. Riau Ujung Pekanbaru \\ email: asiska.permata@univrab.ac.id \\ 2) Sekolah Tinggi Ilmu Kesehatan Fort De Kock \\ J1. Soekarno-Hatta, Bukittinggi
}

\begin{abstract}
Manufacturing of prototype of plastics film for a biodegradable packaging from a mixture of polymer synthetic polystyrene (PS) and polycaprolactone (PCL) has been carried out. Plastics film containing of PS/PCL created by blending techniques followed by solvent casting, the ratios were 100/0, 95/5, 90/10 and 85/15. The resulting of plastic film is a clear sheet with an average thickness of $0.03 \mathrm{~cm}$. The biodegradation rate profile was observed by soil burial test method to see the weight reduction of the plastic films tested for a certain period of time. The results showed that the biodegradation rate profile increased with the addition of PCL with the $t_{50 \%}$ in the 100/0, 95/5, 90/10 and $85 / 15$ ratios respectively being $352.33 ; 91.19 ; 71.97$ and 59.85 weeks, and $t_{95 \%}$ in the 100/0, 95/5, 90/10 and $85 / 15$ ratios were respectively $677.01 ; 177.32 ; 139.43$ and 115.79 weeks. Furthermore, the number of microbes present in each gram of soil is $1.83 \times 105$.
\end{abstract}

Keywords: biodegradation, polistiren, polikaprolakton, soil

\section{ABSTRAK}

Telah dilakukan pembuatan prototipe filem plastik untuk kemasan ramah lingkungan dari campuran polimer sintetik polistiren (PS) dengan biopolimer polikaprolakton (PCL). Filem plastik campuran PS/PCL dibuat dengan teknik blending yang dilanjutkan dengan solven casting dengan perbandingan 100/0, 95/5, 90/10 dan 85/15. Filem plastik yang dihasilkan berupa lembaran bening dengan tebal rata-rata $0,03 \mathrm{~cm}$. Profil laju biodegradasi diamati dengan metode penguburan di dalam tanah (soil burial test) untuk melihat pengurangan berat dari filem plastik yang diuji dalam jangka waktu tertentu. Hasil penelitian menunjukkan bahwa profil laju biodegradasi meningkat dengan penambahan PCL dengan t50\% pada perbandingan 100/0, 95/5, 90/10 dan 85/15 secara berturut-turut adalah 352,33; 91,19; 71,97dan 59,85 minggu, serta t95\% pada perbandingan 100/0, 95/5, 90/10 dan 85/15 secara berturut-turut adalah 677,$01 ; 177,32 ; 139,43$ dan 115,79 minggu. Selanjutnya, jumlah mikroba yang terdapat dalam tiap gram tanah adalah $1,83 \times 10^{5}$.

Kata kunci: biodegradasi, polistiren, polikaprolakton, tanah, 


\section{Pendahuluan}

Perkembangan ilmu pengetahuan dan teknologi, khususnya pada 2 dekade terakhir, telah meningkatkan jumlah penggunaan polimer sintetik. Setiap tahun sekitar 140 juta ton polimer sintetik telah dihasilkan untuk digunakan di berbagai sektor industri. Polimer sintetik sangat berguna karena sifatnya yang kuat, ringan dan daya tahannya yang baik sehingga dapat digunakan untuk berbagai aplikasi [1]. Ironisnya terdapat sifat lain dari plastik yang justru sangat merugikan, yaitu sifatnya yang relatif stabil dan sulit terdegradasi menyebabkan material ini tidak dapat dipertahankan penggunaannya secara meluas karena akan menambah persoalan lingkungan dan kesehatan diwaktu mendatang [2]. Selain itu, polimer sintetik merupakan limbah padat yang telah diketahui sebagai penyebab utama pencemaran lingkungan $[3,4]$

Plastik mudah terbakar, ancaman terjadinya kebakaran pun semakin meningkat. Asap hasil pembakaran bahan plastik sangat berbahaya karena mengandung gas-gas beracun seperti Hidrogen Sianida (HCN) dan karbon monoksida (CO). Hal inilah yang menyebabkan sampah plastik sebagai salah satu penyebab pencemaran udara dan mengakibatkan efek jangka panjang berupa pemanasan secara global pada atmosfer bumi.Selain itu, sampah plastik yang tertimbun di dalam tanah yang tidak dapat diuraikan oleh mikroorganisme, menyebabkan mineral-mineral dalam tanah baik organik maupun anorganik semakin berkurang. Hal ini menyebabkan jarangnya fauna tanah seperti cacing dan mikroorganisme tanah yang hidup pada area tanah tersebut dikarenakan sulitnya untuk memperoleh makanan dan berlindung. Hal lain juga mengakibatkan kadar oksigen dalam tanah semakin sedikit, sehingga fauna tanah sulit untuk bernafas dan akhirnya mati. Ini berdampak langsung pada tumbuhan yang hidup pada area tersebut. Tumbuhan membutuhkan mikroorganisme tanah sebagai perantara dalam kelangsungan hidupnya.

Pemakaian plastik yang dapat diuraikan (biodegradable polymer) atau ramah lingkungan adalah salah satu jalan keluarnya. Polimer biodegradabel (biopolimer), memiliki sifat tahan air yang sangat baik seperti polimer sintetik, bersifat biokompatibilitas dan biodegradabilitas. Penelitian sebelumnya juga telah dilakukan oleh Dewi (2012) tentang pengujian filem plastik campuran polistiren dengan poli (3-hidroksibutirat-ko-3hidroksivalerat) [5]. Jadi pada penelitian ini menggunakan biopolymer yang berbeda yaitu golongan polyester.

Biopolimer yang berasal dari golongan poliéster alifatik seperti poliasamglikolat (PGA), poliasamlaktat (PLA) dan polikaprolakton (PCL) juga banyak dikembangkan saat ini. Pencampuran antara polimer (PS) dan biopolymer (PCL) ini saling menutupi kekurangan satu sama lainnya. PS memiliki kekurangan sulit terdegradasi namun titik lelehnya tinggi dan sifatnya kuat. PCL memiliki biokompatibilitas tinggi dan sifat mekanik yang baik [6], namun titik lelehnya rendah. Berdasarkan sifat ini, diharapkan pencampuran antara PS/PCL dapat menghasilkan poliblend yang kompatibel, kuat, dan dapat terurai di lingkungan.

\section{Tinjauan Pustaka}

\section{Polimer}

Polimer berasal dari bahasa Yunani yaitu poly yang berarti banyak, dan mer yang berarti bagian atau satuan [7]. Polimer merupakan rangkaian molekul panjang yang tersusun dari pengulangan kesatuan molekul yang kecil dan sederhana. Molekul kecil dan sederhana penyusun polimer disebut monomer. Plastik merupakan salah satu contoh polimer yang memiliki massa molekul yang besar yaitu di atas 10.000 [8]. Berdasarkan asalnya, polimer dapat dibedakan menjadi 2 yaitu polimer alam dan polimer buatan. Polimer alam adalah polimer yang bersumber dari alam seperti karet, wol, dan sutra. Sedangkan polimer buatan terdiri dari plastik sintetik yang dibuat melalui polimerisasi monomer-monomer. Menurut Azapagic et al (2003), material polimer yang dominan di pasaran adalah PET (Polietilen tereftalat), PVC (Polivinil klorida), PP (Polipropilen), PE (Polietilen) dan PS (Polistiren) [9].

\section{Biopolimer}

Menurut American Society for Testing and Material (ASTM), biopolimer atau bioplastik adalah bahan yang dapat mengalami perubahan secara alamiah oleh aktivitas mikroorganisme seperti bakteri, jamur, dan alga [1]. Biopolimer merupakan polimer yang berasal dari sumber daya alam yang dapat diperbaharui dan dapat terurai di lingkungan. Biopolimer ini bisa diproduksi oleh mikroorganisme, tumbuhan, hewan atau disintesis secara kimia yang berasal dari material biologis, seperti gula, pati, dan lemak alami [7]. 


\section{Biodegradasi Biopolimer}

Degradasi merupakan perubahan struktur kimia, fisika atau penampilan dari polimer, sedangkan biodegradasi adalah proses penguraian yang terjadi karena aktivitas mikroorganisme. Biodegradasi biopolimer ini dapat terjadi akibat aktivitas enzim dengan memutus rantai ester secara hidrolisis [10]. Hal yang sama juga dikemukakan oleh Tokiwa \& Iwamoto (1994) bahwa biodegradable polymer dapat terurai oleh aktivitas enzim dari bakteri, sedangkan nonbiodegradable polymer sulit diuraikan oleh bakteri sehingga setelah degradasi yang tersisa adalah nonbiodegradable polymer dalam bentuk fragmen-fragmen kecil di lingkungan [11] (Gambar 1).

Gambar 1. Model penguraian filem plastik campuran biodegradable polymer dan non biodegradable polymer

(Tokiwa dan Iwamoto, 1994)

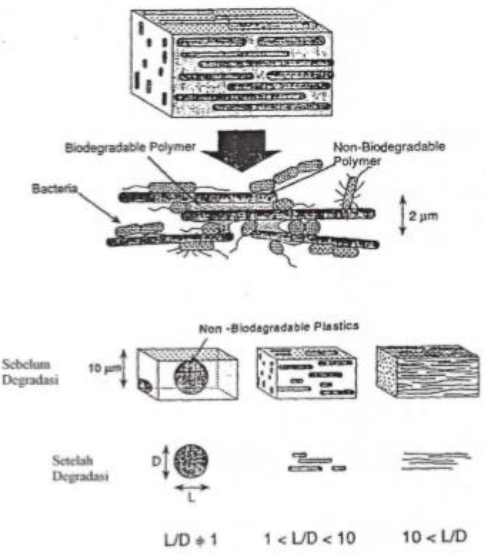

Bahan-bahan bidegradable tersebut diuraikan menjadi biomassa, karbon dioksida, dan metana. Bakteri yang berperan dalam proses biodegradasi, seperti Bacillus, Pseudomonas, Klebsiella, Actinomycetes, Nocardia, Streptomyces, Thermoactino-mycetes, Micromonospora, Mycobacterium, Rhodococcus, Flavobacterium, Comamonas, Escherichia, Azobacter, dan Alcaligenes (beberapa dapat menghasilkan polimer sekitar $90 \%$ dari massa keringnya). Suhu merupakan salah satu faktor penting dalam pertumbuhan mikroorganisme. Faktor penting lainnya adalah sumber karbon, nitrogen, dan $\mathrm{pH}$. Aktivitas jamur dalam proses biodegradasi, seperti Sporotrichum, Talaromyces, Phanerochaete, Ganoderma, Thermoascus, Thielavia, Paecilomyces, Thermomyces, Geotrichum, Cladosporium, Phlebia, Trametes,Candida, Penicillium, Chaetomium, dan Aerobasidium [12].

\section{Metode Penelitian}

a. Alat dan Bahan

Alat-alat yang digunakan antara lain: Hotplate, timbangan analitik, $\mathrm{pH}$ meter, inkubator, colony counter, nampan plastik, kawat, kassa, benang, cawan petri, alat-alat gelas, dan peralatan lainnya.

Bahan-bahan yang digunakan yaitu: polimer (polistiren), biopolymer (polikaprolakton), media NA, pelarut xylene, aquadest, dan alkohol.

b. Pembuatan prototipe poliblend filem plastik dengan berbagai perbandingan

Poliblend filem plastik dibuat dari campuran PS/PCL dengan berbagai perbandingan sebagai berikut :

Formula-1 : PS murni (100\% PS)

Formula-2 : Perbandingan PS/PCL (95:5)

Formula-3 : PerbandinganPS/PCL $(90: 10)$

Formula-4: PerbandinganPS/PCL $(85: 15)$

Setelah masing-masing bahan ditimbang, dilanjutkan dengan pembuatan filem plastik dari masing-masing perbandingan. PS dipotong kecil-kecil, kemudian dimasukkan ke dalam gelas piala. Ditambahkan $10 \mathrm{~mL}$ xylene dan dipanaskan di atas hot plate sampai larut dan mendidih. Setelah itu, ditambahkan PCL ke dalam gelas piala yang sama dan diaduk sampai homogen. Selanjutnya, dituangkan ke dalam cawan petri dan dibiarkan kering pada suhu ruang sehingga diperolah filem plastik. Filem plastik yang terbentuk ditimbang beratnya dan diukur ketebalannya dengan jangka sorong. 
c. Penimbangan masing-masing filem plastik yang dihasilkan dengan berbagai perbandingan

Plastik yang diperoleh dari setiap cawan petri dipotong dengan ukuran $1,5 \times 1,5 \mathrm{~cm}$ dan ditimbang berat masing-masing potongan plastik tersebut. Potongan plastik ini merupakan sampel yang akan diuji penguraiannya dan berat yang ditimbang adalah merupakan nilai berat awal dari masing-masing sampel filem plastik. Untuk setiap pengujian pada setiap perbandingan dilakukan dua kali pengulangan.

d. Penyiapan media uji biodegradasi.

Media uji yang digunakan untuk biodegradasi adalah tanah, yang diambil di jalan Darma Bakti Pekanbaru. Kemudian dibawa ke laboratorium untuk selanjutnya digunakan untuk pengujian biodegradasi.

e. Penentuan biodegradasi filem plastik secara in-vitro

Penentuan kecepatan penguraian filem plastik ini dilakukan secara in-vitro dalam media lingkungan, sesuai dengan metode standar yang direkomendasi oleh American Society for Testing and Materials (ASTM) [13]. Parameter penguraian yang diamati adalah pengurangan berat dari plastik yang diuji setelah dikubur (Soil Burial Test) di dalam tanah dalam jangka waktu tertentu [14]. Masing-masing sampel, dimasukkan ke dalam nampan plastik yang mempunyai panjang $34 \mathrm{~cm}$, lebar $28 \mathrm{~cm}$, dan kedalamannya $13 \mathrm{~cm}$. Daya urai pada tanah dengan metoda uji penguburan: plastik filem dengan ukuran $1,5 \mathrm{~cm} \times 1,5 \mathrm{~cm}$ dari masing masing perbandingan dimasukkan ke dalam tanah sampai terbenam. Setelah periode waktu tertentu sampel diangkat dari tempat perlakuan, dibersihkan dengan air suling dan dikeringkan. Kemudian ditimbang berat filem plastik yang tersisa. Periode waktu pengambilan filem plastik adalah minggu pertama, kedua, ketiga, keempat, kelima, kelima, keenam, dan ketujuh.

f. Pengujian kerapatan populasi bakteri media uji.

Kerapatan bakteri pada masing-masing media uji yang digunakan dilakukan dengan penentuan Angka Lempeng Total (ALT) bakteri yang tumbuh dalam media NA dari suatu sampel yang telah diencerkan terlebih dahulu [15]. Tanah ditimbang sebanyak 1 gram dan disuspensikan dalam $10 \mathrm{ml}$ air suling. Dibuat pengenceran sampai 10-6 dan masing-masing penceran tersebut dituangkan ke dalam cawan petri yang mengandung media NA yang telah memadat dan steril sebanyak $1 \mathrm{ml}$. Kemudian diinkubasi selama 24-48 jam pada suhu $30-35^{\circ} \mathrm{C}$ di dalam inkubator. Dihitung jumlah koloni yang tumbuh dan dikalikan dengan faktor pengencerannya. Hasilnya dinyatakan sebagai Angka Lempeng Total (ALT) dalam tiap gram atau tiap ml sampel.

\section{Hasil Percobaan}

Pembuatan filem plastik campuran polimer (PS) dengan biopolymer (Polikaprolakton) terdiri dari 4 perbandingan $(100 / 0 ; 95 / 5 ; 9010 ; 85 / 15)$. Filem plastik ini dibuat dengan cara blending yaitu mencampurkan antara polistiren dengan polikaprolakton dengan menggunakan pelarut xylene. Filem plastik yang telah dibuat dituang ke dalam cawan petri dan dibiarkan hingga kering. Filem plastik yang dihasilkan berwarna putih agak keruh dengan ketebalan rata-rata $0,03 \mathrm{~cm}$, seperti terlihat pada Gambar 2 .
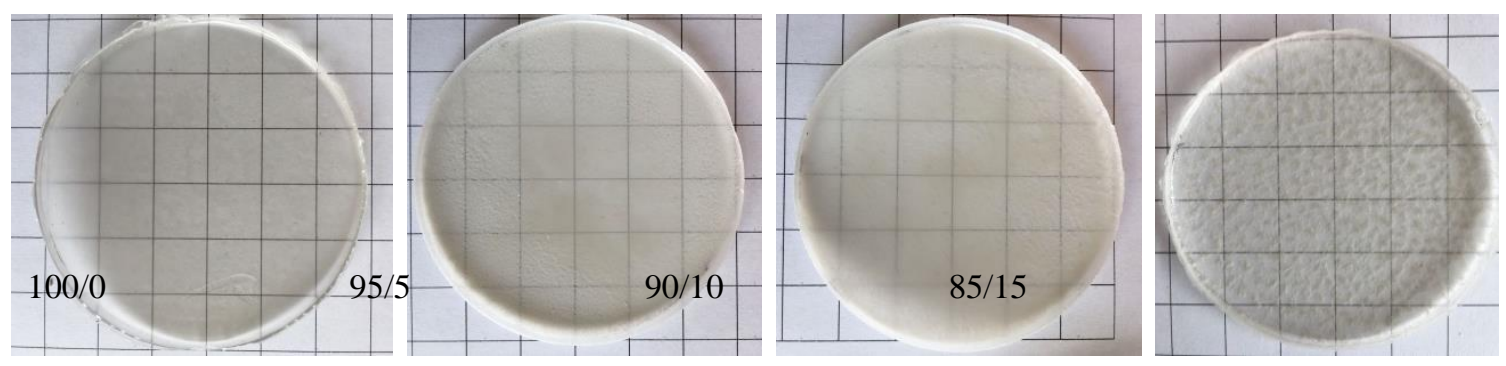

Gambar 2. Filem plastik campuran PS/PCL dengan berbagai perbandingan

$(100 / 0,95 / 5,90 / 10$ dan 85/15)

Selanjutnya, dilakukan pengujian biodegradasi terhadap filem plastik yang telah dibuat. Plastik tiap-tiap perbandingan dipotong dengan ukuran 1.5 x $1,5 \mathrm{~cm}$ dan dimasukkan ke dalam nampan yang berisi tanah dengan panjang $34 \mathrm{~cm}$, lebar $28 \mathrm{~cm}$, dan kedalamannya $13 \mathrm{~cm}$ sampai terbenam. Pengujian biodegradasi ini dilakukan selama 7 minggu. Setelah periode waktu tertentu (setiap minggu), sampel diangkat dari tempat perlakuan, dibersihkan dengan air suling dan dikeringkan. Kemudian ditimbang berat filem plastik yang tersisa. 
Filem plastik yang mengandung polimer sintetis murni (100/0) menunjukkan kecepatan biodegradasi yang sangat lambat dibandingkan campuran dengan biopolimer. Profil biodegradasi pada perbandingan 85/15, 90/10, 95/5, dan 100/0 (dapat dilihat pada Gambar 3). Di samping itu, dapat ditentukan konstanta laju biodegradasi, waktu penguraian 50\% ( $\left.\mathrm{t}_{50 \%}\right)$, waktu penguraian $95 \%\left(\mathrm{t}_{95 \%}\right)$ dari masing-masing filem tersebut. Data ini dapat digunakan untuk menghitung secara teoritis berapa lama filem-filem plastik dengan perbandingan yang berbeda hancur separohnya $\left(\mathrm{t}_{50 \%} \mathrm{~b} / \mathrm{b}\right)$ dan mendekati penguraian total $\left(\mathrm{t}_{95 \%} \mathrm{~b} / \mathrm{b}\right)$. Dalam penghitungan ini tidak digunakan parameter habis sama sekali $\left(\mathrm{t}_{100 \%} \mathrm{~b} / \mathrm{b}\right)$, karena secara teoritis filem plastik tersebut tidak akan pernah habis seratus persen, karena plastik tersebut akan tetap ada walaupun dalam bentuk fragmen-fragmen kecil seperti dikemukakan oleh Tokiwa dkk. (1994) (Gambar 1). Data lengkap \% berat sisa setelah 7 minggu penguraian, perbandingan konstanta laju biodegradasi, waktu penguraian 50\%( $\left.\mathrm{t}_{50 \%}\right)$, waktu penguraian $95 \%\left(\mathrm{t}_{95 \%}\right)$ tertera pada (Tabel 1$)$.

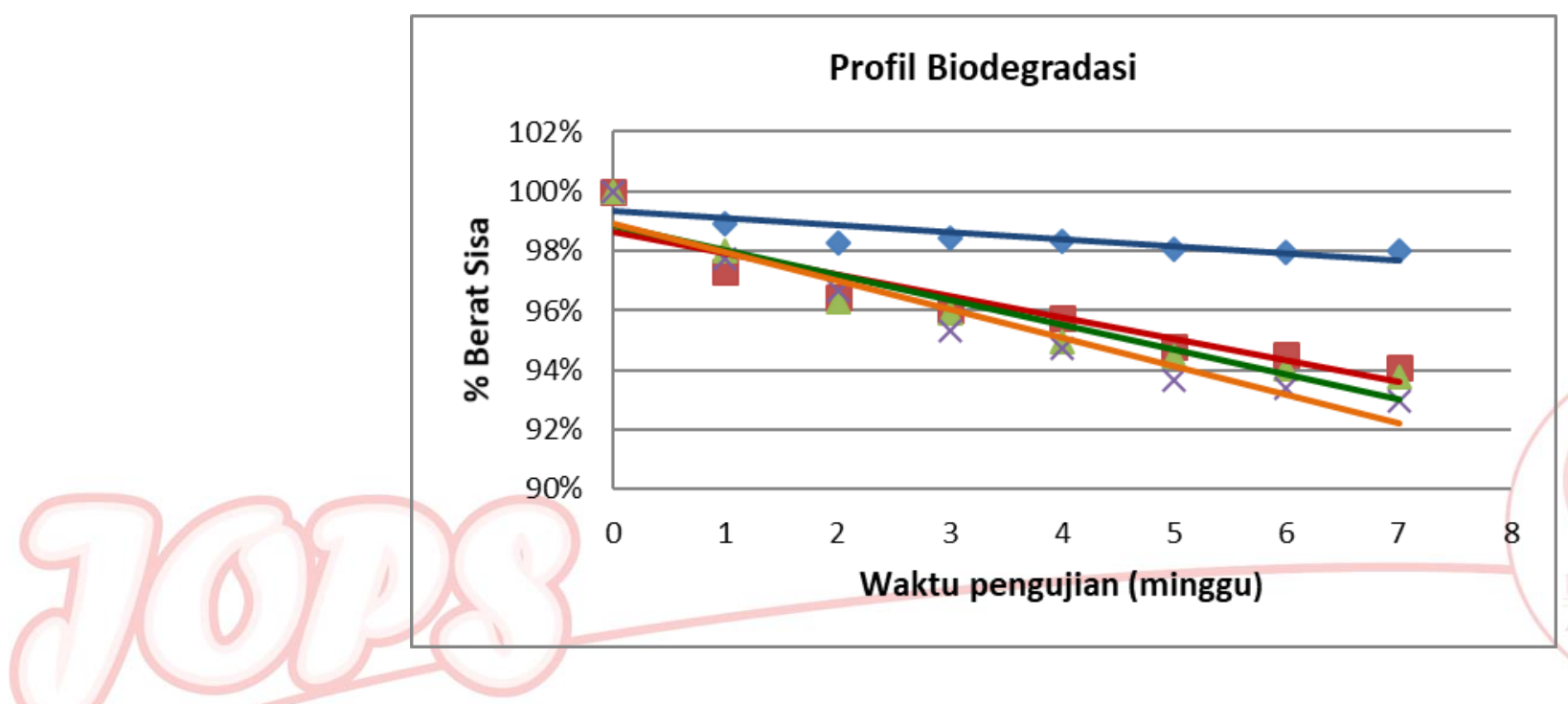

Gambar 3. Profil laju biodegradasi filem plastik campuran PS/PCL pada berbagai perbandingan dalam tanah secara

Keterangan : in-vitro.
$: \mathrm{PS} / \mathrm{PCL}=100 / 0$
- $: \mathrm{PS} / \mathrm{PCL}=95 / 5$
$\triangle: \mathrm{PS} / \mathrm{PCL}=90 / 10$
$\times: \mathrm{PS} / \mathrm{PCL}=85 / 15$

Tabel 1. Konstanta laju biodegradasi (k), waktu penguraian 50\% ( $\left.\mathrm{t}_{50 \%}\right)$, waktu penguraian $95 \%\left(\mathrm{t}_{95 \%}\right)$

\begin{tabular}{|c|c|c|c|c|c|}
\hline No & Perbandingan & $\mathbf{r}$ & $\mathbf{k}$ (\% perminggu) & $\mathbf{t}_{\mathbf{5 0} \%}$ (minggu) & $\mathbf{t}_{\mathbf{9 5}}$ \% (minggu) \\
\hline $\mathbf{1}$ & PS/PCL (100/0) & $-0,8756$ & 0,1386 & 352,33 & 677,01 \\
\hline $\mathbf{2}$ & PS/PCL (95/5) & $-0,9886$ & 0,5225 & 91,19 & 177,32 \\
\hline $\mathbf{3}$ & PS/PCL (90/10) & $-0,9633$ & 0,6671 & 71,97 & 139,43 \\
\hline $\mathbf{4}$ & PS/PCL (85/15) & $-0,9788$ & 0,8043 & 59,85 & 115,79 \\
\hline
\end{tabular}

Pada penentuan Angka Lempeng Total (ALT) pada tanah adalah 1,83 x $10^{5}$ dalam tiap gram sampel. Data kerapatan populasi bakteri ini mempunyai korelasi positif dengan terjadinya pengurangan berat dari sampel filem plastik yang diuji [15]. 


\section{Kesimpulan}

Pada penelitian ini, dapat disimpulkan bahwa:

- Penggunaan biopolimer dalam campuran filem plastik dapat mempercepat terjadinya penguraian di lingkungan dibandingkan dengan polistiren murni.

- Kandungan mikroba yang tinggi yang terdapat dalam media uji di lingkungan, juga mempercepat terjadinya penguraian.

\section{REFERENSI}

1. Katarzyna, L., and Grazyna, L. Polymer Biodegradation and Biodegradable Polymers - A Review. Polish J. of Environ. Stud. 2010; 19: 255-266.

2. Firdaus, F., Mulyaningsih, S. dan Anshory, H. Sintesis Filem Kemasan Ramah Lingkungan dari Komposit Pati, Khitosan dan Asam Polilaktat dengan Pemlastik Gliserol. Studi Morfologi dan Karakteristik Mekanik. 2008; 5: 13-18.

3. Premraj, R. and Mukesh D. Biodegradation of Polymers. Indian Journal of Biotechnology. 2005; 4: 186193.

4. Webb, H.K., Jaimys A., Russell J.C. and Elena P.I. Plastic Degradation and its Environmental Implications with Special Reference ti Poly(ethylene terephthalate). Polymers. 2013; 5: 1-18..

5. AP Dewi, M Octaviani, R Rustini, E Zaini, A Djamaan. 2012. Uji Biodegradasi filem plastic campuran polistiren dengan Poli(3-hidroksibutirat-ko-3-hidroksivalerat) dalam lumpur. Jurnal Sains dan Teknologi Farmasi 17(1) 2012

6. Vaskova, I., Pavol, A., Peter, B., Anna, N., Jozef, F., Tomas, M. Biodegradable Polymer Packaging Materials based on Polycaprolactone, starch and Polyhydroxybutyrate. Acta Chimica Slovaca. 2008; 1: 301-308.

7. Stevens, M. P. 2001. Kimia Polimer. Terjemahan Iis Sopyan. Jakarta: Pradnya Paramita.

8. Suyanto. 2014. Pengantar Kimia Polimer. Surabaya: Airlangga University Press

9. Azapagic, A., A. Emsley, I. Hamerton. 2003. Polymers: The Environment and Sistainable Development. England: John Willey \& Sons Ltd

10. Fukui, T. \&Y. Doi. 1998. Efficient productiom of polyhydroxyalkanoates from plant oil by Alcaligenes eutrophus and its recombinant strain. Applied Microbiology and Biotechnology. 49(3):333-336.

11. Tokiwa, Y. and Iwamoto, A. Enzymatic Degradation of Polymer Blends. Biodegradable plastic and polymers (Eds. Doi Y and Fukuda K). Elsiver Journal of Science. B. V. Amsterdam. 1994: 190-199.

12. Gautam, R., A.S. Bassi, E.K. Yanful \& E. Cullen. 2007. Biodegradation of Automotive Waste Polyester Polyurethane Foam Using Pseudomonas chlororaphis ATCC 55729. International Biodeterioration \& Biodegradation. 60(4):245-249

13. Swift, G. 1994. Expectation for biodegradation testing methods.Biodegradable Plastics and Polymers (Eds. Doi, Y. \& Fukuda, K.), Elsevier Journal of Science. B. V. Amsterdam. 228-249.

14. Sawada, H. 1994. Field Testing of Biodegradable Plastics. Biodegradable Plastic and Polymer, (Eds. Doi, Y. \& Fukuda, K.), Elsevier Journal of Science. B. V. Amsterdam.298-312.

15. Djamaan, A. 2002. Teknologi Produksi Bioplastik. Padang: Jurusan Farmasi FMIPA Universitas Andalas. 